\title{
Integrated reporting - a “one-size-fits-all” solution!?
}

\section{Introduction}

"The world has changed - reporting must too" (IIRC 2011; p. 4). As the information needs of stakeholders have fundamentally changed in recent years, reporting must change too. The worldwide financial crisis has especially illustrated that a separated view on financial and non-financial reporting, as well as an orientation on short-term information, is no longer appropriate for many stakeholders. A solution could be Integrated Reporting (IR) - the symbiosis of financial and non-financial information (Maniora 2013; p. 360). In order to establish this idea, the International Integrated Reporting Council (IIRC) was initiated with the objective to provide quantitative and qualitative guidance in the form of a framework for corporations on how to conduct an integrated report (Müller and Stawinoga 2013; p. 303). One of the main questions that arises in this context is whether IR is "a one-size-fits-all" solution, or if there is a need for sector-specific requirements. Therefore, this article provides not only a theoretical background on what IR is and what it consists of, but also shows some results of experiences examining the reporting habits of several companies that are part of the IIRC's pilot programme to elaborate whether a general framework on IR is sufficient or if there is a necessity to include sector-specific information.

* Dr. Jessica Knoll is a post-doc researcher and lecturer at the chair of banking at Saarland University, Saarbruecken, Germany and partner and CEO of the Institut für Banken und Mittelstandsfinanzierung (Institute for Banking an SME Finance), Saarbruecken, Germany, e-mail: jessica.knoll@bank.uni-saarland.de.

** Anna Feigenbutz is a student researcher at the chair of banking at Saarland University, Saarbruecken, Germany and master student of business administration, e-mail: annafeigenbutz@ad.com 


\section{A theoretical approach on IR}

\subsection{The IIRC and its objectives}

The IIRC is a global coalition of regulators, investors, companies, standard setters, the accounting profession, and non-governmental organizations. The motivation of this council is the modification of existing corporate reporting norms to improve the stream of information between a corporation, its investors, and its other stakeholders. Hence, the mission of the IIRC is to create a globallyaccepted framework that "elicits from organizations material information about their strategy, governance, performance, and prospects in a clear, concise, and comparable format" (IIRC 2012; p. 4). The framework aims to underpin and accelerate the evolution of corporate reporting in order to connect financial reporting, governance and remuneration, management commentary, and sustainability reporting, and to reveal their interdependencies. On top of that, the IIRC encourages the acceptance and adoption of IR by report preparers and aims to gain the recognition of investors and standard setters (IIRC n.y. IASB and IIRC...) Therefore, the IIRC's long term vision is a world in which integrated thinking is embedded within business practices facilitated by IR as the corporate reporting norm (IIRC 2013; p. 2). To achieve this goal, the IIRC published the International Integrated Reporting Framework in December 2013. To support the idea of IR, the IIRC introduced a pilot programme, and the organizations participating in this programme are able to test principles, content, and the practical application of IR (IIRC n.y. Pilot Programme...).

\subsection{Characteristics of IR}

"To make our economy sustainable, we have to relearn everything we have learned from the past. That means making more from less and ensuring that governance, strategy, and sustainability are inseparable" (IIRC 2010). Bearing this in mind, the IIRC defines IR as "a concise communication about how an organization's strategy, governance, performance, and prospects (in the context of its internal and external environment) lead to the creation of value over the short, medium, and long term" (IIRC 2013; p. 7).

The four main objectives of IR are:

1) improve the quality of information available for providers of financial capital to enable a more efficient and productive capital allocation;

2) accelerate a moreefficient approach to corporate reporting that illustrates the full range of factors that create value over time and connects various reporting strands; 
3) enhance accountability and stewardship and promote interdependencies between them;

4) support integrated thinking, decision-making, and further actions that rivet on value creation over the short, medium, and long term (IIRC 2013; p. 2).

To support companies in the process of IR, the framework establishes fundamental concepts, guiding principles, and content elements that help organizations express their unique value-creation story in a meaningful and transparent way. The framework does not prescribe benchmarks, specific indicators, or measurement methods to be used in an integrated report. Rather, it functions as a principles-based approach that creates a balance between flexibility and the prescription of relevant information. Through continuous application to all relevant reports and communication tools, the credibility and acceptance of IR will be expedited (IIRC 2013; p. 8).

The fundamental concepts of IR involve deliberations regarding value creation for a corporation and for others. These concepts should provide an overview of:

- an organization's strategy, its activities, and the affection of an organization by its environment (incl. legal, commercial, social, environmental, and political aspects);

- the resources and activities used and affected by an organization;

- the interaction of an organization with its environment and its capitals to create value over time (IIRC 2013; pp. 6, 14, 24).

The IIRC also specifies six guiding principles that can be divided into two categories. While the first group of principles - "materiality and conciseness", "reliability and completeness", and "consistency and comparability" - derive from generally-accepted accounting principles, the other principles - "strategic focus and future orientation", "connectivity of information", and "stakeholder responsiveness" - focus on different aspects (Müller, Stawinoga 2013; p. 305).

Furthermore, an integrated report includes various content elements:

- organizational overview and external environment,

- governance,

- opportunities and risks,

- strategy and resource allocation,

- business model,

- performance,

- outlook.

These content elements are closely linked to each other and are not considered to be a standard structure; they should, rather, emphasize the connections between these elements (IIRC 2013; p. 24). 


\subsection{IR vs. financial reporting}

"Capitalism needs financial stability and sustainability to succeed. Integrated Reporting will underpin them both, leading to a more resilient economy" (Diplock n.y.). Per definition, financial reporting is based on the annual report, which includes annual accounts and a management report, as well as further voluntary reports; e.g., sustainability or corporate responsibility reports (Pellens n.y.). Financial reporting is currently challenged by providing a picture of a company's performance and does not contain sufficient information on non-financial performance. As a result, organizations publish (i.e.) sustainability reports separated from their financial reports (Eccles and Saltzman 2011; p. 57).

IR "builds on the strengths of financial and sustainability reporting while enabling assimilation of new knowledge, new issues, and new metrics that flow from the social, environmental, and economic dynamics in the $21^{\text {st }}$ century" (White 2010; p. 29). Thus, an integrated report can deal with the complexity of economic and societal progresses more appropriately, and can use diverse beneficiaries to satisfy all stakeholder's needs that are (i.e.) based on greater transparency, integrated thinking, and the consideration of information over time (White 2010; p. 29).

\section{The use of IR with focus on diverse sectors}

Concerning the sector-specific implementation of IR, the authors examined six German companies from different industrial sectors that are part of the IIRC's pilot programme and, therefore, should be conducting an IR:

1) chemicals (BASF SE),

2) banks (Deutsche Bank),

3) software and computer services (SAP),

4) transportation services (Flughafen München $\mathrm{GmbH}$ ),

5) electricity (EnBW Energie Baden-Württemberg AG),

6) financial provider (Deutsche Börse Group).

A detailed analysis of these six organizational disclosures shows that, even though all of these companies are familiar with IR and are currently working on implementing IR into their reporting procedures, all of these companies are at different stages of implementation. Apart from that, each of the analyzed organizations implement IR in its own individual way; this especially becomes clear in the different amount of content, the different usage of IR-related terminology, the stage of implementation of the guiding principles and content elements, and 
the contexture of visual elements in an IR. Also, the companies' measures to "sell and advertise" their IR differ; some organizations have individual IR-websites, while others only link their IR to multi-media platforms.

\section{IR-requirements}

\subsection{General requirements}

The heart of IR is the integrated report that not only provides a better understanding of a company's performance for the stakeholders; it is also a management tool that helps organizations meet the requirements of a global economy, environment, and society by combining information on a company's financial and non-financial performance and revealing interdependencies between them (Krzus 2011; p. 271).

Within an organization, IR can only be successful when:

- IR and integrated thinking are implemented in all processes and hierarchies,

- the corporation is aware of opportunities and risks in the medium and long terms, and builds a strategy that is capable of utilizing opportunities,

- the board of an organization is interested in operating in an integrated way (Burghardt 2013; p. 15).

To implement IR into a company's business model, there are several steps to take:

- defining its business model by considering all relevant capitals that are relevant to a company's performance and explaining their role in the company's value creation process;

- assessing opportunities and risks and the operating context by analyzing a company's value chain, considering financial, social, environmental, economic, governance issues and trends, defining strategic objectives that fulfill stakeholder expectations and sustainability issues as well as material KPIs that have an impact on company performance;

- adapting business processes by implementing and adding organizational changes and establishing integrated thinking;

- establishing integrated reporting by publishing selected information that meets stakeholder needs (PwC, Integrated Reporting - The Future... 2012; p. 10).

After IR is fully implemented, a single integrated report addressing short, medium, and long term business values will tell a company's value creation story, 
show dependencies between financial on non-financial capital, and provide assessment of business value and stewardship to its investors (KPMG 2012; p. 7).

\subsection{Sector-specific requirements}

It is not only necessary to cast a glance at general requirements, but also on sector-specific requirements regarding IR, because several sectors face different non-financial issues (GRI n.y. G3/G3.1). However, sector-specific requirements concerning the IR-process are associated with the challenge to determine material KPIs to cope with inconsistencies in the quality of non-financial reporting. Thus, the development of sector-specific guidelines can be advantageous to improve a company's ability to report on their ESG performance and to promote the comparability and practicability of KPIs (Eccles et al. 2012; p. 13). The IIRC has not yet considered sector-specific requirements in its framework, but there are several approaches dealing with the coverage of sector-specific requirements.

According to the G3/G3.1 Sector Supplements (GRI n.y.), airport operators (on the one hand) are requested to report i.e., on the impact on local communities through measuring and monitoring impacts on biodiversity and aircraft noise. On the other hand, financial services are requested to report i.e., on the product portfolio, active ownership performance, and sale of financial products. These sector supplements elucidate diverse requirements on each company's report relevant to a particular sector. Furthermore, it is important for stakeholders to review information that helps them compare an organization to its competitors, aiming to understand its current and future position in an industrial sector (Cohen et al. 2012; p. 68).

\section{IR - a critical approach}

"In their current practices, $90 \%$ of companies have already adopted elements of integrated reporting" (PwC, Integrated Reporting in Germany... 2012; p. 6). According to a study conducted by PwC, many German companies describe their performance fundamentals well; however, the linkage of external drivers, corporate strategy, and the explanation and measurement of actual and future performance could need some improvement (PwC, Integrated Reporting in Germany... 2012; p. 6). Moreover, the raising sensitization of the populace concerning the rate of an entrepreneurial sense of responsibility necessitates organizations to align the requirements of company publicity. The IIRC accommodates these changes while presenting a relatively abstract framework which establishes a broad latitude, containing both chances and risks (Müller and Stawinoga 2013; p. 309). 
According to the IIRC's discussion paper, implications of IR will vary for different participants (i.e., reporting organizations, investors, policy-makers, regulators, and standard-setters). The benefits of IR may also be relevant to other stakeholders, such as customers, suppliers, and governments "who are increasingly demanding demonstration of a more integrated picture of performance as a prerequisite for doing business" (IIRC 2011; p. 21). Generally, IR can lead to some positive changes in an organization:

- better connected departments, i.a., creating internal linkages;

- improved internal processes leading to a better understanding of the business, i.a., resulting in a greater understanding of how an organization creates value by identifying and responding to opportunities, risks, and changes;

- increased focus and awareness of senior management, i.a., greater focus on sustainability issues and better-informed decision making;

- better articulation of its strategy and business model, i.a., the linkage of nonfinancial and financial KPIs;

- creating value for stakeholders, i.a., improved stakeholder relations by satisfying their needs and by providing better ESG information for stakeholders (Krzus 2011; p. 275].

However, IR also bears various risks:

- fundamental challenges concerning the measurability, reliability, and integrity of integrated reports may be neglected due to the disclosure of wasteful less-relevant information [Eccles et al. 2012; p. 8];

- new challenges and additional costs concerning the preparation of annual reports, as financial and non-financial information and integrated thinking have to be assembled and the support of senior management is needed (Müller and Stawinoga 2013; p. 309);

- IR offers new challenges for existing audit and assurance processes, as auditors will be confronted with new forms of reports and information (Adams and Simnett 2011; p. 299).

- reconciliation of the IIRC's requirements with national and international legislators as the "Memorandum of Understanding" (an agreement between the IIRC and IASB) aims to support the improvement of quality and consistency of global corporate reporting (Müller and Stawinoga 2013; p. 309).

Considering the chances and challenges above, the question if IR is a "one-size-fitsall" solution can neither be affirmed nor negated. Indisputably, IR connects both financial and non-financial information which results in a more holistic, overall picture of a business (Jensen and Berg 2011; p. 300). Though the IIRC released a framework, it seems to be expedient to further specify the principles-based 
approach of the framework in order to provide additional, detailed, cross-sectoral requirements respectively support clarification necessary to ensure that it will be consistently applied by report preparers in a way that meets stakeholder needs most effectively (Müller and Stawinoga 2013 p. 309). This implies (e.g.) the inclusion of examples into the framework (Kajüter and Hannen 2013). A solution to these discrepancies might be a definition of minimum requirements that must be achieved in order to have a "real" integrated report. Another substantial yet unconsidered addition to the IIRC Framework is a list of sectorspecific requirements. By providing sector-specific requirements, indicators that are relevant for particular organizations can show both a more-comprehensive picture of a company's value creation process and support for the definition of materiality (Streck 2013).

\section{Prospect}

"Integrated Reporting is the evolution of financial reporting" (SAICA 2011). Considering the progress of IR on the international level, it becomes clear that it is applied in notable ways: over 450 companies listed on the Johannesburg Stock Exchange have been obligated to prepare an integrated report in exchange for separated annual financial and sustainability reports since March 2010; if they refuse to do so, they need to justify themselves (KPMG 2012; p. 8). The French Commercial Code requires that both listed and non-listed companies (commencing with the annual report on December $31^{\text {th }}, 2012$ ) include a broad quantity of sustainability information in their management report (Noodt and Greda 2013; p. 715). Several examples can be stated. The stage of IR in Germany is promising, too:

- the German Commercial Code already contains regulations approaching IR in the norms concerning the management report;

- the formulation of the DRS 20 implies the implementation of IR-elements in a management report (Behncke et al. 2012; pp. 3063-3068);

- the generally-accepted GRI Sustainability Reporting Framework and Guidelines that were designed to be applied by organizations from different sectors (GRI n.y. About Sustainnability...).

It is evident that IR is a present, pioneering topic that is relevant for both national and international organizations. Fundamental premises have been resolved in previous years. How the future of IR (esp. a sector-specific realization) can be arranged still remains to be seen (IIRC n.y. Key Milestones...). Therefore, the collaboration between the IIRC and (i.a.) GRI, IASB, SASB, and the European 
Integrated reporting - a "one-size-fits-all" solution!?

Commission, as well as the integration of IR into various international and national legislations, determines the further process of IR (Noodt, Grede 2013; p. 716). Thus, "the journey towards Integrated Reporting will be unique for each organization" (Adams and Simnett 2011; p. 300).

\section{Conclusion}

Beyond question, the trend towards IR will continue, whereas it must be recognized that the concept of IR is not entirely new and can be seen (i.a.) as a natural extension of many principles of environmental or green accounting and sustainability reporting (Owen 2013; p. 354).

The IIRC released its framework in December 2013, and further improvements will surely follow. The development of IR will be time consuming: on the one hand, the implementation of IR does not consist of a simple "stringing together" of existing reports, but it will cause more in-depth changes within a company and its infrastructure. On the other hand, the process of IR is additionally dependent on national and international legislative decisions (Noodt and Grede 2013; p. 716). Furthermore, the acceptance of IR by accounting and audit departments (as well as by the stakeholders) is important (Müller and Stawinoga 2013; p. 309).

Heretofore, companies have to trade off opportunities and risks of whether to implement IR into their business or not. For instance, IR is able to present financial and non-financial information and to connect various departments more efficiently, and is, therefore, recommendable.

As the previous findings show, IR is not necessarily a "one-size-fits-all" solution, and might need sector-specific norms. However, IR can advance - if successfully implemented into the national and international legislation - the "urgent vision for business to create value for both the company and society, thereby contributing to lasting prosperity on a healthy planet" (Krzus 2011; p. 276).

\section{References}

[1] Adams, S. and Simnett, R. (2011) 'Integrated Reporting: An Opportunity for Australia's Not-for-Profit Sector', Australian Accounting Review, vol. 21, pp. 292-301.

[2] Behncke, N., Hoffmann, T. and Wulf, I. (2012) 'DRS 20: Auf dem Weg zum Integrated Reporting', Betriebsberater, vol. 49, pp. 3063-3068.

[3] Burghardt, M. (2013) 'Integrated Reporting: Lohnt sich der zusätzliche Aufwand für Kreditinstitute?', Zeitschrift für das gesamte Kreditwesen, vol. 11, pp. 13-15. 
[4] Cohen, J., Holder-Webb, L., Nath, L. and Wood, D. (2012) 'Corporate Reporting of Nonfinancial Leading Indicators of Economic Performance and Sustainability', Accounting Horizons, vol. 26, pp. 65-90.

[5] Diplock, J. (n.y.) Statement on IR, [Online], Available: http://www.theiirc.org [29 Apr 2014].

[6] Eccles, R. and Saltzman, D. (2011) 'Achieving Sustainability Through Integrated Reporting', Stanford Social Innovation Review, pp. 56-61.

[7] Eccles, R., Krzus, M., Rogers, J. and Serafeim, G. (2012) 'The Need for Sector-Specific Materiality and Sustainability Reporting Standards', Journal of Applied Corporate Finance, vol. 24, pp. 8-14.

[8] GRI (n.y.) About Sustainability Reporting, [Online], Available: https://www. globalreporting.org/information/sustainability-reporting/Pages/default.aspx [29 Apr 2014].

[9] GRI (n.y) G3/G3.1 Sector Supplements, [Online], Available: https://www. globalreporting.org/reporting/sectorguidance/sector-guidance/Pages/default. aspx [29 Apr 2014].

[10] IIRC (2010) Formation of the International Integrated Reporting Committee (IIRC), [Online], Available: http://www.theiirc.org/wp-content/uploads/ 2011/03/Press-Release1.pdf [29 Apr 2014].

[11] IIRC (2011) Towards Integrated Reporting - Communicating Value in the $21^{\text {st }}$ Century, [Online], Available: http://theiirc.org/wp-content/uploads/2011/09/ IR-Discussion-Paper-2011_spreads.pdf [29 Apr 2014].

[12] IIRC (2012) Financial Statements, [Online], Available: http://www.theiirc.org/ wp-content/uploads/2013/07/IIRC-FINANCIAL-STATEMENTS-31-DECEMBER2012.pdf [29 Apr 2014].

[13] IIRC (2013) Consultation Draft of the International IR Framework, [Online], Available: http://www.theiirc.org/wp-content/uploads/Consultation-Draft/ Consultation-Draft-of-the-InternationalIRFramework.pdf [29 Apr 2014].

[14] IIRC (n.y.) IASB and IIRC formalise cooperation on work to develop integrated corporate reporting framework, [Online], Available: http:/www.theiirc.org/2013/02/07/iasb-and-iirc-formalise-cooperation-on-work-to-developintegrated-corporate-reporting-framework/ [29 Apr 2014].

[15] IIRC (n.y.) Key Milestones for IR, [Online], Available: http://www.theiirc.org/ about/the-work-plan [29 Apr 2014].

[16] IIRC (n.y.) Pilot Programme Business Network, [Online], Available: http:// www.theiirc.org/companies-and-investors/pilot-programme-business-network/ [29 Apr 2014].

[17] Jensen, J. and Berg, N. (2011) 'Determinants of Traditional Sustainability Reporting Versus Integrated Reporting', Business Strategy and the Environment, vol. 21, pp. 299-316. 
[18] Kajüter, P. and Hannen, S. (2013) Consultation Draft Submissions, [Online], Available: http://www.theiirc.org/wp-content/uploads/2013/08/135_Universityof-M\%C3\%BCnster-Chair-of-International-Accounting.pdf [29 Apr 2014].

[19] KPMG (2012) Integrated Reporting - Performance insight through Better Business Reporting, [Online], Available: http://www.kpmg.com/Global/ en/IssuesAndInsights/ArticlesPublications/integrated-reporting/Documents/ integrated-reporting-issue-2.pdf [10 Oct 2013].

[20] Krzus, M. (2011) 'Integrated reporting: if not now, when?', Internationale Rechnungslegung, vol. 6, pp. 271-276.

[21] Maniora J. (2013) 'Integrated Reporting - Vom Diskussionspapier zum Konsultationsentwurf des IIRC', Kapitalmarktorientierte Rechnungslegung, vol. 7, pp. 360-369.

[22] Müller S., Stawinoga M. (2013) 'Integrierte Berichterstattung: Aufstellung und Prüfung eines integrierten Berichts vor dem Hintergrund aktueller Verlautbarungen des IIRC', Kapitalmarktorientierte Rechnungslegung, vol. 6, pp. 303-309.

[23] Noodt, A. and Grede, J. (2013) 'Die Welt ändert sich - die Rechnungslegung auch: Der Weg zur integrierten Berichterstattung', Der Betrieb, vol. 14, pp. $714-717$.

[24] Owen, G. (2013) 'Integrated Reporting: A Review of Developments and their Implications for the Accounting Curriculum', Accounting Education, vol. 22, pp. 340-356.

[25] Pellens, B. (n.y.) Definition Geschäftsbericht, [Online], Available: http:// wirtschaftslexikon.gabler.de/Definition/geschaeftsbericht.html [29 Apr 2014].

[26] PwC (2012) Integrated Reportingin Germany-The DAX-30 BenchmarkStudy, [Online], Available: http://www.pwc.de/de_DE/de/rechnungslegung/assets/pwcstudie-integrated-reporting-in-germany-2012.pdf [29 Apr 2014].

[27] PwC (2012): Integrated Reporting-The Future ofCorporate Reporting, May 2012, [Online], Available: http://www.pwc.de/de_DE/de/rechnungslegung/assets/ integrated_reporting.pdf [29 Apr 2014].

[28] SAICA (2011) An integrated report is a new requirement for listed companies, [Online], Available: https://www.saica.co.za/tabid/695/itemid/2344/language/ en-ZA/An-integrated-report-is-a-new-requirement-for-list.aspx [29 Apr 2014].

[29] Streck, M. (2013) Consultation Draft, [Online], Available: http://www.theiirc. org/wp-content/uploads/2013/08/083_Flughafen-M\%C3\%BCnchen-GmbH. pdf [29 Apr 2014].

[30] White, A. (2010) 'The Five Capitals of Integrated Reporting: Toward a Holistic Architecture for Corporate Disclosure', in Eccles R., Cheng B., Saltzman D. (ed.), The Landscape of Integrated Reporting, Cambridge: Harvard Business School. 
